\title{
AMELIORATION OF BUILDING MICROCLIMATES THROUGH LANDSCAPE DESIGN APPROACHING HOT-HUMID CLIMATE
}

\author{
NACHAWIT TIKUL \\ Faculty of Architecture and Environmental Design, Maejo University, San Sai, Chiang Mai 50290, Thailand \\ E-mail: nachawit@gmail.com
}

\begin{abstract}
Saving energy in buildings has become a more important issue in various countries. One strategy that can reduce the cooling load in buildings is landscaping and environmental design. However, it is difficult to estimate the amount of influence of landscape, environment and their elements on ambient temperature. Therefore, the purpose of this study is to examine the relationship between landscape elements and outdoor temperature. The arrangement in relation to temperature reduction is also determined. From the study, it was found that the first important factors that helped to reduce the ambient temperature were water elements, followed by mature trees and groundcover areas. In addition, the outdoor area should be minimally open ground and a hard surface area. The proper placement of each element should be considered specifically the water area should be placed on the south or south-west. The groundcover should be placed next to the building and trees should be placed on the south, east and west sides. The width of canopy of mature trees should be at least 4.5 meters, and evergreen trees should be at least 6 meters of height and dense. Besides these, there are many other variables, such as building layout, building shapes and building materials that may have some effects on the ambient temperature, and they will be studied later.
\end{abstract}

Index Terms - Ambient temperature, building, hot-humid climate, landscape design, passive design

\section{INTRODUCTION}

The building sector is responsible for about $30-45 \%$ of the total energy consumption of the global energy demand [1]. Buildings consume energy indirectly and directly in all phases of their life cycle right from the cradle to the grave. The operating energy during occupancy phase has a major share (80-90\%) in the life cycle energy use of buildings [1,2]. It is required for maintaining comfort conditions that are usually the energy for ventilation and cooling systems for buildings in the regions having a hot and humid climate [2] such as Thailand. Therefore, the building sector has become the focus on energy reduction initiatives to achieve more sustainable development in various countries $[3,4]$. Long term energy savings can be fulfilled by improving the building design and building technology as well as conserving energy during the operation phase [5] and energy optimization of HVAC systems is particularly important [6]. Therefore, advances in technology are increasing to achieve the desired reduction in energy consumption goals but this does not necessarily lead to an overall reduction [7].

One of the green design approaches to cooling buildings by natural means is the passive cooling strategy. This strategy involves a controller that limits the total effect of the heat gain to provide an indoor temperature lower than that of the natural surroundings [7]. Energy-efficient building design can be made by orientation and size of windows or transparent building elements, building forms, shading, thermal insulation material selection, using natural ventilation, etc. [8]. In addition, the environmental design around the building to reduce the air temperature before entering the building is also important, because it can help to reduce the cooling load in the building as well $[9,10]$. Landscaping has always played an important role in modifying the building environment. In addition, it becomes a strategy to offer protection from the most severe conditions imaginable and reducing surrounding temperature through shade trees and the process of soil evaporation and plant transpiration. Plants are able to absorb heat energy by releasing water vapor [9]. However, landscape design guidelines will be recommended in terms of tree positioning and choosing the sizes and shapes of the trees. Therefore, it is difficult to estimate the numbers of trees to be planted and the amount of influence of landscape and its elements on ambient temperature [11]. This study aims to examine the importance and relationship of landscape elements with outdoor temperatures and their arrangement in relation to the temperature reduction.

\section{METHODOLOGY}

This study was a preliminary stage of a research study to determine the landscaping ability to reduce surrounding temperature and associated energy consumption in buildings. The study results were from a summary and collation of secondary data sources. The sources included previous research reports, magazines and journals as well as government and private company statistics that involved landscaping designs to reduce ambient temperature.

\section{RESULTS}

A. Landscape elements and land cover proportion Elements of general landscaping include the hard landscape(hardscape), such as paths, walls, water features, sitting areas and decking, and soft landscape (softscape) elements, known as plants, pattern of 
plantations, flowers and others. Usually, hardscape refers to hard surface elements such as concrete, wood and rocks, while, softscape is the living elements on landscape designs [10, 12]. In the aspect of the influence of landscape design for reducing outdoor thermal comfort, studied by Bonan [13] and $\mathrm{Yu}$ [14], it was found that softscape and water are the important elements of landscape design. This aspect usually applies to various plants such as matured trees, shrubs and grass, and water elements which have potential to improve the outdoor thermal comfort due to their shade and humidity [15]. According to Dimoudi and Nikolopoulou, it was found that, of all the landscape design elements, vegetation is the most effective factor and plays a role in surface and air temperature modification [16]. In other studies such as Bonan, Givoni, Pearlmutter and co-workers, they found that grass or mulching area and water element increase humidity around the building and then have an effect on cooling temperature $[17,13,8]$. Therefore, the combination of shade trees, groundcover areas and water elements was predictably found to be the most effective landscape strategy. Although water is an artificial facility, a shallow pond, a small waterfall, and a spray fountain can create an air temperature decline area on the leeward side [8]. Shashua and co-workers [18] found that efficient landscape design can reduce air temperature more than $30 \mathrm{C}$ before entering the building and it can reduce cooling costs by about 30\% [16]. Small waterfalls or spray fountains scattered at various points around the building can reduce the temperature before entering the building by $33.33 \%$ [14]. In addition, Tominaga et al. found that evaporative cooling can reduce pavement surface temperature near the building by approximately $2 \mathrm{oC}$ [19]. Various previous studies found that the pavement surface characteristics around the building affect the temperature. For example, if the ambient temperature is about $40 \mathrm{oC}$, asphalts pavement surface would have a temperature of about $42 \mathrm{oC}$ and the concrete surface temperature would be about 45oC [15]. According to a study by Xiaoshan Yang and Lihua Zhao [20], it was found that the surface temperatures of the concrete and granite slab pavements are significantly higher than those of softscape and water surfaces throughout the daytime period. Surfaces of lawn soil and the grass leaves are hotter than that of the pond during the daytime. Therefore, when the wind blows over the concrete surface, it would be about 5oC higher temperature than the ambient temperature in the building. However, if the wind blows over the grass surface, the temperature of the air flow is about 1 to $2^{\circ} \mathrm{C}$ cooler than that of the over bordering areas. Misting the grass with a fine spray of water to raise humidity around a lawn, would decrease its surface temperature about $80 \mathrm{C}$ lower than that of a dry grass surface temperature. In addition, in high shade areas of a wet lawn, the surface temperature would be about $2 \mathrm{oC}$ cooler than that of an open wet lawn during the maximum temperature of the day.
From a study by Wanpen [21], she established a few multiple regression models providing a possible solution to reduce urban temperature by means of determining the proper proportion of land covering urban areas. The results show a significant positive correlation between the build-up area and temperature and a negative correlation between vegetation and water-covered land and temperature. A model was calibrated with some existing data and the answers were similar to the others. Therefore, the model can be applied in landscaping design process for reducing ambient temperature as shown in equation (1). The model demonstrates that for every percent, if increased by land covered by trees, water areas ( 1.5 meters deep), and lawn areas could result in a $0.028^{\circ} \mathrm{C}$, $0.053^{\circ} \mathrm{C}$ and $0.009^{\circ} \mathrm{C}$ decrease in temperature. The temperature would rise by $0.022^{\circ} \mathrm{C}$ and $0.016^{\circ} \mathrm{C}$ if the building area or hardscape and ground are increased in every 1 percent of the surrounding area. Therefore, if the building has 100 square meters of space, the outside temperature would be $40^{\circ} \mathrm{C}$. The 10 square meter grassy area of a total 50 square meter area would reduce the temperature to about $38.7^{\circ} \mathrm{C}$.

$T_{2}=T_{1}+0.022 * X_{1}+0.016 * X_{2}-0.028 * X_{3}-0.053 * X_{4}-0.009 * X_{5}$
Where,
$\mathrm{T}_{2}=$ modified temperature $\left({ }^{\circ} \mathrm{C}\right)$
$\mathrm{T}_{1}=$ ambient temperature $\left({ }^{\circ} \mathrm{C}\right)$
$\mathrm{X}_{1}=$ percent of hard surface pavement areas to surrounding areas
$\mathrm{X}_{2}=$ percent of brown areas to surrounding areas
$\mathrm{X}_{3}=$ percent of tree areas to surrounding areas
$\mathrm{X}_{4}=$ percent of water areas to surrounding areas
$\mathrm{X}_{5}=$ percent of lawn areas to surrounding areas

\section{B. Plants selection}

The focus vegetation for reducing the temperature around the building consists of 2 groups, namely, trees and mulching plants such as grass or bean sprouts. The characteristics of the trees selected for this purpose include genetic variability, foliage color and density, overall form, growth rate (both fast and slow growing plants may be desired) and ability to grow and survive under a hot-humid climate [22]. For a hot-humid climate area, shading from the trees is very important. The most suitable trees characteristically have spreading crowns, dense foliage and provide excellent shade. Therefore, the canopy diameter of mature trees should be at least 4.5 meters and the height should be over 6 meters. In addition, they should be evergreen trees and dense at the top of the trees, but the lower part should be airy to allow the wind to blow through. The dense canopy trees should block out over 70-90\% of the sunlight [23].The ability to withstand drought is a factor that must be considered when landscaping in the summertime. In addition, invasive alien species and exotic pest plants should not be used. There are many examples of temperate trees for this purpose as shown in Table 1. 
Amelioration of Building Microclimates Through Landscape Design Approaching Hot-Humid Climate

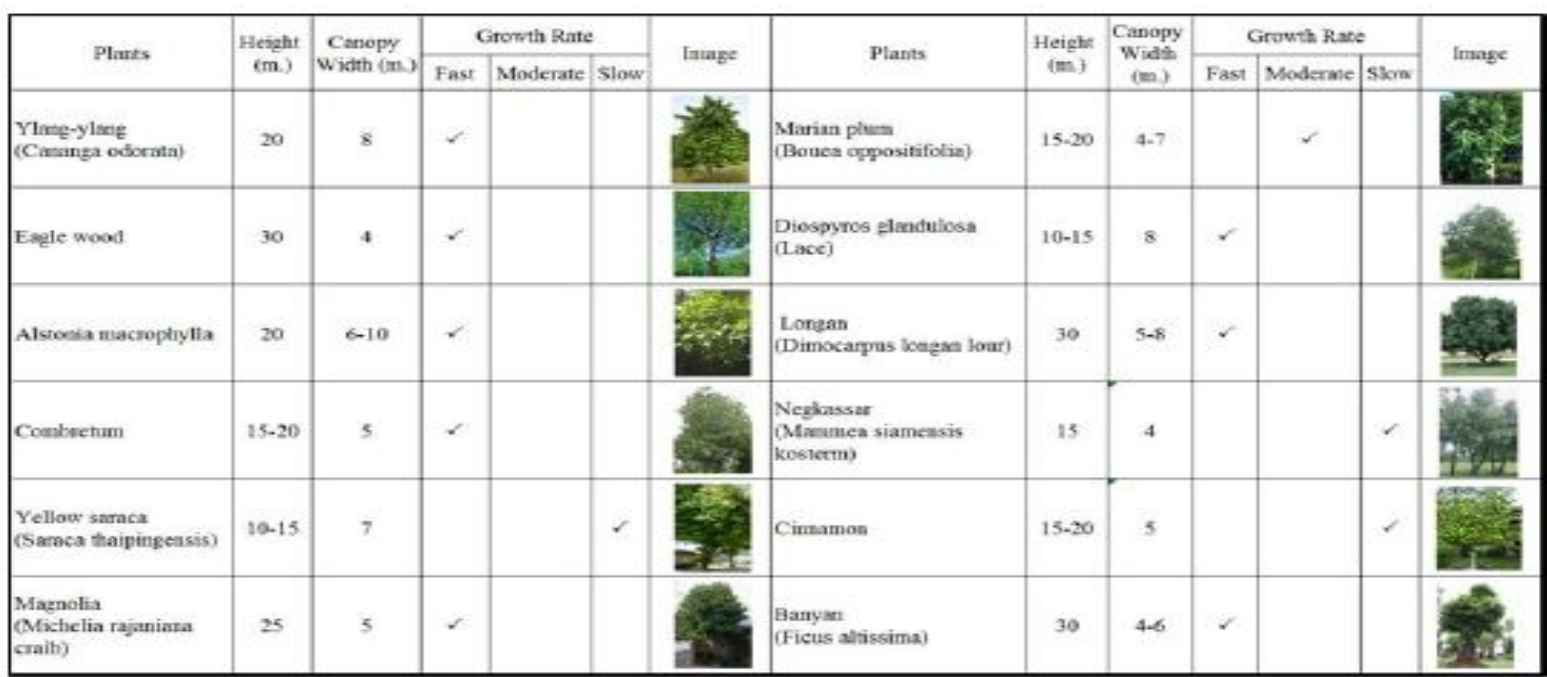

Table 1 Some temperate trees used in landscaping in hot-humid area

\section{Function and Position of Landscaping Design Elements}

The layout for the modification of temperature in different climate zones needs different designs. This study focuses on the hot-humid climate where Tucson [24] and Attia's study [25] found plantings on the west and south sides of homes tend to provide the most cooling in summer, while plantings on the north side actually increase the heat load, perhaps by blocking winds. In the second category of Thai's Rating of Energy and Environmental Sustainability (TREES) which is cited, the landscape category requires planting mature trees on 3 sides of the building i.e. east, west and south, and the gap between the canopy of mature trees should be less than 1 meter apart for effective shading.

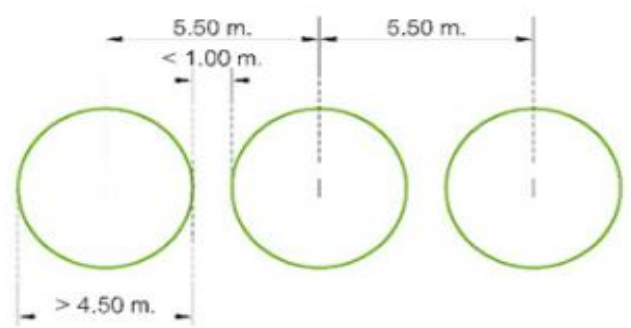

Figure 1 Mature tree placement in landscape design for shading

The trees at 3-5 meters from the building provide shade on the roof and trees 6-10 meters from the building provide shade on the wall. However, the trees should be planted far enough away from the building so that when they are mature, their root systems do not damage the building's foundation and branches do not damage its roof. Shrub plants (1.00-1.50 m. high) help to shade on the west and south walls which face to low-angle sunlight to warm the building and to control wind direction by obstruction, guidance, deflections, and filtration though the windows or voids. Figure 2 shows the placing impact of height differences of large bushes or rows of shrubs with differing distances from the windward wall of a building with window openings. The low shrubs at the building causes airflow to drop inside the building. This conditions provide positive natural ventilation and air mixing characteristics inside buildings. In addition, the placing distances generate secondary eddies; when shrub-hedges are placed some distance from the windward side of the building, lee eddies of relatively calm air are created. Groundcover plants (0.30-0.90 m. high) can also shade the ground and pavement. They should cover the pavement or ground around the building on the east, west and south sides. Water areas, such as a shallow pond, a small waterfall, and a spray fountain should be placed under trees and in front of windows and voids of the building i.e. in the south and south-west.
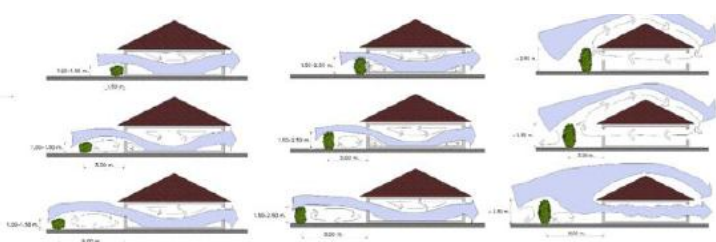

Figure 2 The impacts of shrub's height and placing distance on wind direction and eddies

\section{DiscuSSION AND CONCLUSION}

The result of this paper demonstrates that landscape design helps to improve the microclimate surrounding a building. The landscape design elements such as the quadripartite layout, water, vegetation and walls should be all integrated in the building landscape as a way of passive cooling. Important factors that help to reduce the ambient temperature for tropical areas such as Thailand should include water elements, wet areas, trees, and groundcover areas. The objectives are for increasing humidity and shading, and reducing heat reflections from hard cover and open ground area around the building. It was found that humidity from water elements has the most potential to decrease ambient temperature. The water elements can be a natural pond, an artificial pond, a small waterfall, or a 
spray fountain. In addition, the proper position of these water elements should be included in the design. The proper placement of the each element should be; specifically the water area should be placed on the south or south-west. The groundcover should be placed next to the building and trees should be placed on the south, east and west sides. The trees should be at least $4.5 \mathrm{~m}$ in canopy diameter and higher than $6 \mathrm{~m}$. They should be evergreen trees and dense at the top. However, the reduction in ambient temperature also depends on many other variables, such as building layout, building shape and building materials. These variables will be studied later.

\section{ACKNOWLEDGEMENT}

Financial support from the Biodiversity-Based Economy Development Office (BEDO) for this research project is gratefully acknowledged.

\section{REFERENCES}

[1] D. Asimakopoulos, M. Santamouris, I. Farrou, L. M., S. M., G. Zanis, G. Giannakidis, K. Tigas and J. Kapsomenakis, "Modelling the energy demand projection of the building sector in Greece in the 21 st century," Energy Build., no. 49, p. 488-498, 2012

[2] M. Asif, T. Muneer and R. Kelley, "Life cycle assessment: a case study of a dwelling home in Scotland," Building and Environment, no. 42, p. 1391-1394, 2007.

[3] E. Azar and C. Menassa, "A comprehensive analysis of the impact of occupancy parameters in energy simulation of office buildings," Energy Build., no. 55, p. 841-853, 2012.

[4] T. Nguyen and M. Aiello, "Energy intelligent buildings based on user activity: a survey," Energy Build., no. 56, p. 244-257, 2013.

[5] C. Thormark, "A low energy building in a life cycle-its embodied energy, energy need for operation and recycling potential," Building and Environment, no. 37, p. 429-435, 2002.

[6] C. Short, K. Lomas and A. Woods, "Design strategy for low-energy ventilation and cooling within an urban heat island," Build Res Inf., no. 32, p. 187-206, 2004.

[7] N. Geetha and R. Velraj, "Passive cooling methods for energy efficient buildings with and without thermal energy storage-A review," Energy Edu. Sci. Technol. Part A: Energy Sci. Res., no. 29, p. 913-946, 2012.

[8] B. Givoni, Passive Low Energy Cooling of Buildings, New York: John Wiley \& Sons, 1994.

[9] S. Ramesh, "Energy Efficient Landscape for Thermal Comfort in Buildings and Built-up Areas," International Journal of Engineering and Technology, no. 8(5), 2016.
[10] J. Williams and K. Tilt, "Residential Landscape Design," 2006. [Online]. Available: www.aces.edu. [Accessed 6 May 2015].

[11] S. Leuzinger, R. Vogt and C. Korner, "Tree surface temperature in an urban environment," Agricultural and Forest Meteorology, no. 150, p. 56-62, 2010.

[12] N. H. Mohd Hussain and S. Ahmad, "Malay Landscape: Typical Design for Contemporary House at Desa Wawasan," Asian Journal of Environment-Behaviour Studies, no. 1(3), pp. 37-47, 2010.

[13] G. Bonan, "The microclimates of a suburban Colorado (USA) landscape and implications for planning and design," Landscape and Urban Planning, no. 49, p. 97-114, 2000.

[14] C. Yu and W. Hien, "Thermal benefits of city parks," Energy and Buildings, no. 38, pp. 105-120, 2006.

[15] I. Saito, O. Ishihara and T. Katayama, "Study of the effect of green areas on the thermal environment in an urban area," Energy and Buildings, no. 15, p. 493-498, 1991.

[16] A. Dimoudi and M. Nikolopoulou, "Vegetation in the urban environment: microclimate analysis and benefits," Energy and Buildings, no. 35, p. 69-76, 2003.

[17] D. Pearlmutter, E. Kruger and P. Berliner, "The role of evaporation in the energy balance of an open-air scaled urban surface," International Journal of Climatology, no. 29, p. 911-920, 2009.

[18] L. Shashua-Bar, E. Erell and D. Pearlmutter, "The cooling efficiency of urban landscape strategies in a hot dry climate," Landscape and Urban Planning, no. 92, p. 179-186, 2009.

[19] Y. Tominaga, Y. Sato and S. Sadohara, "CFD simulations of the effect of evaporative cooling from water bodies in a micro-scale urban environment: Validation and application studies," 2015.

[20] X. Yang and L. Zhao, "Thermal Behavior of Pavements, Vegetation, and Water Pond in a Hot-Humid City," Buildings Journal, no. 6, 2016.

[21] W. Charoentrakulpeeti, "Impact of Land Cover on Atmospheric Temperature in Bangkok," NIDA Journal of Environmental Management, no. 8(1), 2012.

[22] Forestry Department, "Landscape and Ornamental Trees," [Online]. Available: http://www.fao.org/docrep/005/y4351e/y4351e07.htm. [Accessed 12 February 2016].

[23] I. Hidayat, "The Ecological Role of Trees and their Interactions in Forming the Microclimate Amenity of Environment," Jurnal Bumi Lestari, no. 10, pp. 182-190, 2010.

[24] M. Shahidan and P. Jones, "Plant canopy design in modifying urban thermal environment: theory and guidelines," in The 25th Conference on Passive and Low Energy Architecture, Dublin, 2008.

[25] S. Attia, "The Bioclimatic Zones Concept: Landscape Design Strategy for Site Planning in Hot Arid Climate," Smart and Sustainable Built Environment, 2009. 